\title{
Nocardia nova
}

National Cancer Institute

\section{Source}

National Cancer Institute. Nocardia nova. NCI Thesaurus. Code C86616.

A species of aerobic, Gram-positive, rod shaped bacteria assigned to the phylum

Actinobacteria. This species is nonmotile, catalase and urease positive, reduces nitrate,

does not produce phosphate and utilizes glucose and fructose as its only carbon source.

$\mathrm{N}$. nova is found in the soil and is a causative agent of nocardiosis. 